\title{
BROOKHGWEN
}

NATIONAL LABORATORY

BNL-96364-2011-IR

\section{Beam Loading Computation for the IDS-NF FFAG}

\author{
J. Scott Berg
}

September 2011

Physics Department

Brookhaven National Laboratory

\section{U.S. Department of Energy Office of Science}

Notice: This manuscript has been authored by employees of Brookhaven Science Associates, LLC under Contract No. DE-AC02-98CH10886 with the U.S. Department of Energy. The publisher by accepting the manuscript for publication acknowledges that the United States Government retains a non-exclusive, paid-up, irrevocable, world-wide license to publish or reproduce the published form of this manuscript, or allow others to do so, for United States Government purposes. 


\section{DISCLAIMER}

This report was prepared as an account of work sponsored by an agency of the United States Government. Neither the United States Government nor any agency thereof, nor any of their employees, nor any of their contractors, subcontractors, or their employees, makes any warranty, express or implied, or assumes any legal liability or responsibility for the accuracy, completeness, or any third party's use or the results of such use of any information, apparatus, product, or process disclosed, or represents that its use would not infringe privately owned rights. Reference herein to any specific commercial product, process, or service by trade name, trademark, manufacturer, or otherwise, does not necessarily constitute or imply its endorsement, recommendation, or favoring by the United States Government or any agency thereof or its contractors or subcontractors. The views and opinions of authors expressed herein do not necessarily state or reflect those of the United States Government or any agency thereof. 


\title{
Beam Loading Computation for the IDS-NF FFAG
}

\author{
J. Scott Berg ${ }^{1}$ \\ Brookhaven National Laboratory; Building 901A; P.O. Box 5000; Upton, NY 11973-5000
}

\begin{abstract}
I accumulate the information we have for the current baseline design for a neutrino factory to determine the maximum current we can expect at the final FFAG accelerating stage. I then determine the energy extracted from the RF cavities in the FFAG, and from that determine how much time there must be between bunch trains to restore the energy to the RF cavities so that each bunch train has the same energy at the storage ring. I also estimate the amount of energy variation from the head to the tail of the bunch train.
\end{abstract}

Key words: beam loading, neutrino factory, proton driver PACS: 29.27.Bd

\section{Beam Current from Front End}

From the ISS accelerator report [1], the total number of muons per proton per $\mathrm{GeV}$ of proton kinetic energy is approximately 0.017 . In [2], the maximum production of mesons up to a point before the cooling channel is approximately 0.035 mesons per proton per $\mathrm{GeV}$ of proton kinetic energy. From [3], the ratio of this merit factor to the same factor into the neutrino factory acceptance at the end of a cooling channel is approximately 1.92. Thus, this figure corresponds to a number of muons per proton per $\mathrm{GeV}$ of proton kinetic energy of approximately 0.019. From the data underlying those calculations, it seems that the precise number is closer to 0.020 [4]. We assume that we have 3 pulses every $20 \mathrm{~ms}$ and a $4 \mathrm{MW}$ proton driver. Taking the largest figure for the muons per proton per $\mathrm{GeV}$, we find a number of muons in each bunch train at the end of the cooling channel going into the accelerator acceptance of

\footnotetext{
Email address: jsberg@bnl.gov (J. Scott Berg).

URL: http://pubweb.bnl.gov/ j jserg/ (J. Scott Berg). 1 Work Supported by the United States Department of Energy, Contract No. DE-AC02-98CH10886.
}

$3.3 \times 10^{12}$

\section{Decay Losses in Acceleration}

Decay losses in the earlier acceleration stages will reduce the current seen in the FFAG. There are three acceleratio stages preceding the FFAG: a linac and two recirculating linar accelerators (RLAs).

The linac consists of three sections, with the following parameters $[5,6]$ :

\begin{tabular}{lllr}
\hline Lattice cell length $(\mathrm{m})$ & 3 & 5 & 8 \\
Lattice cell count & 6 & 8 & 11 \\
Cavities & 1 & 1 & 2 \\
Cells/cavity & 1 & 2 & 2
\end{tabular}

Energy gain/cell (MV) 11.25 12.75 12.75

Power input/cell (kW) $490 \quad 508 \quad 508$

RF pulse length (ms) $\quad \begin{array}{llll}3 & 3 & 3\end{array}$

The $\overline{\mathrm{RF}}$ phase decreases from $72^{\circ}$ to $0^{\circ}$ approximately linearly down the channel [7]. Note that the energy gains appear to have no correction for the reduction in transit time factor at lower velocities. 
For these calculations that can be treated as being folded into the phase.

To compute decay losses, one must integrate the simultaneous equations

$$
\begin{aligned}
& \frac{d N}{d s}=-\frac{m c^{2} N}{c \tau \sqrt{E^{2}-\left(m c^{2}\right)^{2}}} \\
& \frac{d E}{d s}=q V(s) \cos \phi(s)
\end{aligned}
$$

where $N$ is the number of muons, $E$ is the muons' total energy, $s$ is the longitudinal position, $m$ is the muon mass, $\tau$ is the muon lifetime at rest, and $c$ is the speed of light. The result is $94.4 \%$ transmission.

The RLA designs [5] appear to have $3 \mathrm{~m}$ halfcells cells containing a single two-cell cavity with an energy gain of $25.5 \mathrm{MV}$ per cavity. See the linac table for the corresponding power parameters. The first RLA has 26 such cells, the second has 88 such cells. The first RLA arc appears to be $130 \mathrm{~m}$ long for an energy of $1.2 \mathrm{GeV}$. The lengths of subsequent arcs are assumed to scale with the momentum. Each RLA accelerates in 4.5 passes.

Decay losses are computed by taking

$$
N=N_{0} \exp \left(-\frac{m c^{2} L}{c \tau \sqrt{E^{2}-\left(m c^{2}\right)^{2}}}\right)
$$

in the arcs and

$$
N=N_{0}\left(\frac{E+\sqrt{E^{2}-\left(m c^{2}\right)^{2}}}{E_{0}+\sqrt{E_{0}^{2}-\left(m c^{2}\right)^{2}}}\right)^{-\frac{m c^{2}}{c \tau q v}}
$$

in the linacs. Zero subscripts indicate initial values, $L$ is the length of the arc, and $v$ is the accelerating gradient in the linac. The transmissions in the two RLAs (treating the transfer line as a fifth arc) are $89.0 \%$ and $89.2 \%$ respectively.

Thus, with the decay losses, we expect $2.5 \times 10^{12}$ muons to reach the FFAG in each bunch train.

\section{Energy Extracted from RF Cavities}

From the Study II report [6], superconducting cavities were proposed that had a maximum energy gain per cavity of $25.5 \mathrm{MV}$ and an input power of $1016 \mathrm{~kW}$. In our likely configuration, a triplet with $5 \mathrm{~m}$ drifts, the beam will make 12 passes through some of the cavities.

Therefore, assuming the maximum energy gain, the $2.5 \times 10^{12}$ muons extract $122 \mathrm{~J}$ from each cavity in 12 passes. To replenish that energy will at the input power rate available for the cavity will require $120 \mu \mathrm{s}$.
The stored energy in the Study II cavity [6] was 2008 J. On each pass, the bunch train extracts $10.2 \mathrm{~J}$ from the cavity. Thus, the last bunch in the train sees $65 \mathrm{kV}$ less $\mathrm{RF}$ voltage than the first bunch, receiving $0.25 \%$ less energy gain than the first bunch. Therefore, the last bunch in the train will finish the acceleration cycle with an energy $31 \mathrm{MV}$ lower than the first bunch in the train.

\section{References}

[1] The ISS Accelerator Working Group et al, JINST 4 (2009) P07001.

[2] X. Ding, D. Cline, H. Kirk, and J. S. Berg, OPTIMIZED PARAMETERS FOR A MERCURY JET TARGET, to appear in Proceedings of PAC09, Vancouver, BC, Canada (2009).

[3] X. Ding, Optimized Target Parameters for Mercury Jet, presentation at the $2^{\text {nd }}$ Oxford-Princeton High-Power Target Workshop, Princeton, NJ, 6-7 November 2008.

[4] H. Kirk, private communication (2010).

[5] The IDS-NF Collaboration, "First progress report," IDSNF-017 (2010). https://www.ids-nf.org/

[6] S. Ozaki, R. Palmer, M. Zisman, and J. Gallardo, eds., Feasibility Study-II of a Muon-Based Neutrino Source, Brookhaven National Laboratory report BNL52623 (2001).

[7] J. S. Berg et al., Phys. Rev. ST Accel. Beams 9, 011001 (2006). 